\title{
microRNA detection in feces, sputum, pleural effusion and urine: Novel tools for cancer screening (Review)
}

\author{
YU-FENG XIAO, XIN YONG, YA-HAN FAN, MU-HAN LÜ, SHI-MING YANG and CHANG-JIANG HU \\ Department of Gastroenterology, Xinqiao Hospital, Third Military Medical University, Chongqing 400037, P.R. China
}

Received February 2, 2013; Accepted April 15, 2013

DOI: $10.3892 /$ or.2013.2525

\begin{abstract}
RNAs (miRNAs) are short non-coding RNA sequences that play important roles in the regulation of gene expression. They have significant regulatory functions in basic cellular processes, including differentiation, proliferation and apoptosis. miRNAs are differentially expressed in tumors, compared with normal tissues. Importantly, miRNAs are also stable and abundantly present in body fluids and feces. The high reproducibility, sensitivity and specificity of miRNAs in body fluids and feces enable miRNAs to be used as potential molecular markers for cancer screening. An increasingly large number of research studies have reported the role of miRNAs in this field. In the present review, we focused mainly on the application of detecting miRNAs in stool, sputum, pleural effusion and urine, to detect colon, lung and urological cancers, highlighting the role of miRNAs in early diagnosis and prognosis.
\end{abstract}

\section{Contents}

1. Introduction

2. Fecal miRNA detection in colon cancer screening

3. Sputum and pleural effusion miRNA detection in lung cancer

Correspondence to: Dr Shi-Ming Yang or Dr Chang-Jiang Hu, Department of Gastroenterology, Xinqiao Hospital, Third Military Medical University, Chongqing 400037, P.R. China

E-mail: shimingyang@yahoo.com

E-mail: hcj6699@yahoo.com

Abbreviations: microRNA, miRNA; NSCLC, non-small cell lung cancer; FOBT, fecal occult blood test; BTA test, bladder tumor antigen test; NMP22, nuclear matrix protein 22; BC, bladder cancer; CRC, colorectal cancer; CTC, CT colonography; CT, computed tomography; MPE, malignant pleural effusion; UC, urothelial carcinoma; EMT, epithelial-mesenchymal transition; ERBB4, epidermal growth factor receptor; COX-2, cyclooxygenase-2; APC, adenomatous polyposis coli; UTI, urinary tract infection

Key words: microRNAs, feces, sputum, pleural effusion, urine, cancers
4. Urine miRNA detection in urological cancer

5. Common methods used in miRNA diagnosis

6. Conclusions and prospects

\section{Introduction}

Cancer is currently the most lethal human disease. Lung and colorectal cancers are the first and third most common types of cancers and the leading causes of cancer-related mortality worldwide (1). Bladder cancer, a urological cancer, is the second most common malignancy that involves the urinary system, and the clinical outcome is often poor once the tumor becomes invasive (2). Although much progress has been made in the prevention, early diagnosis and treatment of cancer, survival rates are still not optimistic, indicating that a more powerful method to detect cancer in the early stages is needed.

Early detection of cancer has been reported to greatly improve both the survival rate and prognosis, suggesting that the key to oncotherapy may lie in early diagnosis (3-7). Thus, developing a method for the early detection of cancer is both important and necessary. Ideally, an early detection method would have high sensitivity, specificity and repeatability, and would be safe, affordable and acceptable to the patient as well.

Traditional methods, such as colonoscopy (8), bronchoscopy (9) and cystoscopy (10), are used to detect colon cancer, non-small cell lung cancer (NSCLC) and bladder cancer, respectively. These methods have greatly benefited many individuals in the past and they are still used to diagnose cancer. However, their use has been hampered by their invasive nature, the manpower resources they require, their high cost and the discomfort they cause patients (11-13).

Biological screening methods, including the fecal occult blood test (FOBT) for colon cancer; sputum cytology for NSCLC (14); and the bladder tumor antigen (BTA test), BTA stat test, nuclear matrix protein 22 (NMP22), and urinary cytology for bladder cancer, have also been applied in recent years. However, these methods each have a significant sensitivity $(15,16)$ or specificity $(13)$, but not both.

As previously mentioned, these methods have drawbacks that prevent their wide application. However, miRNA research in recent years has shed new light on early stage cancer detection. miRNAs can function as oncogenes and tumor suppressors (17). Many studies have reported that miRNA levels are altered during cancer (18-20), suggesting that 


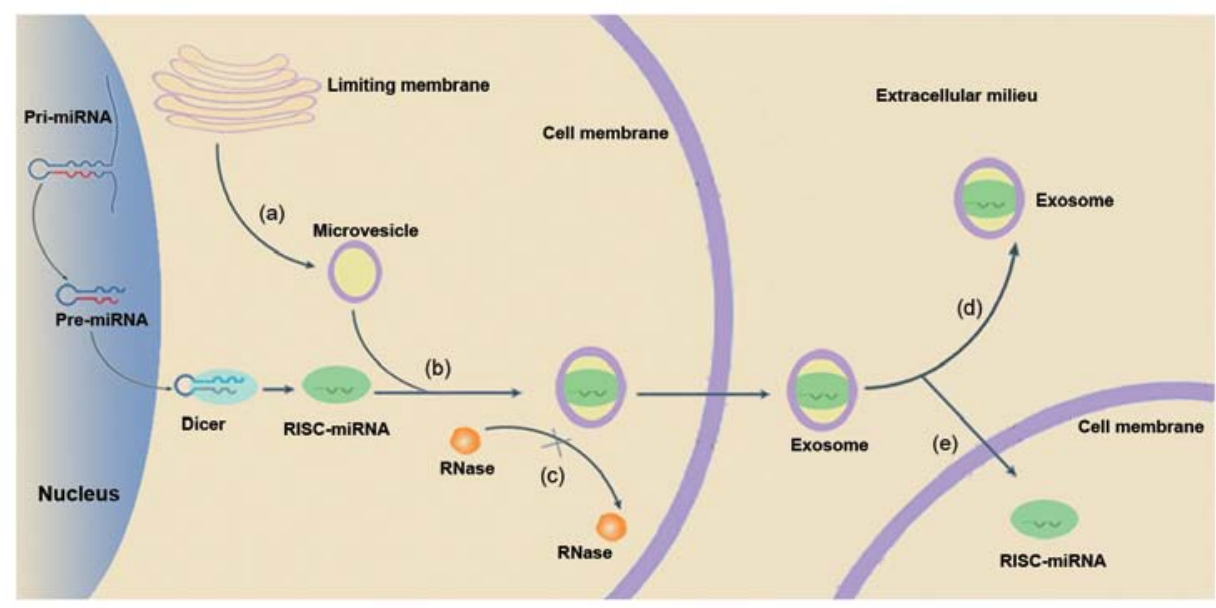

Figure 1. Microvesicles help protect miRNAs against degradation by RNase and help miRNAs pass through the cell membrane into the extracellular milieu. (a) Inward budding and scission of vesicles from the limiting membrane. (b) miRNAs hide themselves in the microvesicles. (c) Microvesicles help to protect miRNAs against degradation by RNase. (d) Exosomes remain stable in the extracellular milieu. (e) miRNAs are carried into adjacent cells to regulate and control cellular processes.

miRNA dysregulation may be the perfect tool for the early diagnosis of cancer.

miRNAs are short, non-coding RNA sequences of 20-22 nucleotides that are involved in crucial biological processes, such as development, differentiation, apoptosis and proliferation (21-23). Each miRNA has numerous gene targets, and miRNAs mainly function by pairing with the 3'-untranslated regions of target mRNAs (24). Nevertheless, a recent study reported that miR-34a modulates MDM4 expression via a target site in the open reading frame (25). According to existing data, miRNAs regulate at least $30 \%$ of protein-coding genes (26) suggesting that miRNAs may control cellular processes in this manner.

This review discusses the possibility of detecting miRNAs in feces, sputum, pleural effusion and urine in order to screen for certain types of cancer, such as colon, lung and bladder cancers, respectively. These three body fluids and stool have been widely used to detect diseases in the clinic for many years, and the results of their biochemical indices have high diagnostic value. These materials have the advantages of reproducibility, abundant content and tissue-specificity.

With the development of genetic sequencing tools, many researchers have realized that traditional clinical detection methods cannot make full use of the genetic value of these materials. Notably, we found that many studies have focused on the potential use of miRNAs in these materials as biomarkers to detect cancer. microRNAs in these materials are useful candidates for cancer detection for the following reason: miRNAs in body fluids and stool are stable under extreme conditions, including a range of temperatures and $\mathrm{pH}$ values, after extended storage and after multiple freeze-thaw cycles (27-32), indicating that miRNAs in these materials are stable enough to detect even after the time of collection. However, synthetic miRNAs can be quickly degraded by RNase in the plasma (28). Brase et al (33) hypothesized that miRNAs hide in microvesicles, which protect them against RNase activity, resulting in their stability (Fig. 1). Microvesicles are small particles that are released into the cellular space and blood stream from cell membranes $(34,35)$. Evidence indicates that mRNAs and miRNAs can be transported through microvesicles between cells (36). Furthermore, these encapsulated miRNAs have been found to be involved in the regulation of hematopoiesis and cellular differentiation (37). Microvesicles, also known as exosomes, have been correlated with both cancer stage and miRNA levels in primary cancers when secreted into the extracellular milieu $(29,38)$, suggesting that exosomes can be used to transport genetic information, such as miRNAs, to support tumor growth and progression (39). Additionally, there is another mechanism that can explain miRNA stability. Certain miRNAs have been reported to bind to a specific DNA/RNA-binding protein to avoid degradation (40). miRNAs have been abundantly detected in the stool, sputum, pleural effusion and urine, suggesting that changes in the expression levels of miRNAs can be easily detected. Xie et al (41) showed that miRNAs were more stable than RNA molecules, despite significant miRNA deposition. Evidence has shown that miRNAs can act as oncogenes and tumor suppressors. Therefore, changes in miRNA content may indicate that cancer is present.

In the present study, we summarize the value of miRNAs in three body fluids and stool for the early diagnosis and prognosis of tumors.

\section{Fecal miRNA detection in colon cancer screening}

Colorectal cancer (CRC) is the third most common cancer worldwide and the leading cause of cancer-related mortality. Approximately $50 \%$ of patients will die from the development of distant metastases, and the survival rate over a 5-year period is $\sim 40 \%$ after diagnosis and treatment (1). However, early detection of such neoplasms leads to a better prognosis. There are several methods for detecting CRC, but their drawbacks have limited their wide application and dissemination worldwide. Colonoscopy is the gold standard for CRC diagnosis. However, the limitation outlined previously (including the invasiveness of the procedure, the high cost of the equipment and the manpower required), have restricted the wide application of this procedure. Furthermore, clinical guidelines suggest that 
Table I. Summary of the characteristics of miRNAs in the stool.

\begin{tabular}{|c|c|c|c|c|c|c|}
\hline miRNA & Refs. & Dysregulation (stool) & Specificity (\%) & Sensitivity (\%) & Samples & Normalization \\
\hline $\operatorname{miR}-144^{*}$ & (57) & Upregulated & 87 & 74 & 75 & miR-378 \\
\hline $\operatorname{miR}-92 \mathrm{a}$ & $(30)$ & Upregulated & 73.3 & 71.6 & 246 & RNU6B \\
\hline miR-21 & (30) & Upregulated & 73.3 & 55.7 & 246 & RNU6B \\
\hline $\operatorname{miR}-21$ & $(21)$ & Upregulated & -- & -- & 37 & miR-16 and miR-26b \\
\hline miR-135 & $(31)$ & Upregulated & 95 & 46.2 & 340 & U6 snRNA \\
\hline miR-17-92 & $(31)$ & Upregulated & 81.5 & 69.5 & 340 & U6 snRNA \\
\hline $\mathrm{miR}-34 \mathrm{~b} / \mathrm{c}$ & (59) & Upregulated & 87.2 & 75 & 67 & RNU19 and RNU6B \\
\hline miR-148a & (59) & Upregulated & -- & -- & 67 & RNU19 and RNU6B \\
\hline miR-106a & (21) & Upregulated & -- & -- & 37 & $\mathrm{miR}-16$ and $\mathrm{miR}-26 \mathrm{~b}$ \\
\hline miR-145 & $(58)$ & Downregulated & -- & -- & 51 & miR-16 \\
\hline miR-143 & $(58)$ & Downregulated & -- & -- & 51 & miR-16 \\
\hline
\end{tabular}

'--' not mentioned in the original study.

colonoscopic screening should begin at the age of 50. However, over $80 \%$ of these individuals could potentially be spared the procedure as no relevant lesions are found $(42,43)$. The FOBT is one of the most commonly used biological methods, but its effects are undesirable. The sensitivity of a single FOBT to detect CRC is only $30-50 \%$ (44), indicating that a substantial number of neoplasms may be missed (45). One meta-analysis also reported that FOBT screening reduces the relative risk of CRC-related mortality by $\sim 16 \%$ (46), suggesting that FOBT may not be an ideal method for the diagnosis of CRC. Compared with colonoscopy, CT colonography (CTC) has the advantage of reducing the side effects and drawbacks of colonoscopy, including bleeding and cardiorespiratory events. CTC also has a high sensitivity and specificity of 55-90\% and $86-96 \%$, respectively (47-50). However, the sensitivity of CTC decreases as the size of the polyps decrease (50). In short, CTC is a useful method for colon cancer screening, aside from the low sensitivity in the detection of small polyps and the high cost.

Another promising approach for the early detection of $\mathrm{CRC}$ is the analysis of molecular biomarkers, such as mRNA and DNA in stool. One study showed that COX-2 mRNA could be detected in 26 out of 29 CRC cases (90\% sensitivity) (51). In fecal DNA-based testing, which was developed in the early 1990s, a number of genes in the stool, including APC, p53 and K-Ras, are used as targets for CRC identification (45). The diagnostic sensitivity of this test ranged from 52 to $94 \%$ for CRC detection (52), and the specificity ranged from 93 to $97 \%(53,54)$. However, fecal mRNAs and DNA degrade easily due to the activity of RNase and DNase, limiting the wide application of this test (55). In addition, the cost of sDNA (stool DNA) screening can be as high as $\$ 800$ (56), which is another factor limiting the widespread use of the test.

miRNAs are short non-coding RNA sequences that play an important role in the regulation of gene expression. Aberrant gene expression can alter miRNA expression in cancer cells (21). Changes in miRNA expression can be observed in many types of cancers, including CRC (57). Many studies have reported that miRNAs are detectable in the stool
(Table I). Stool-based miRNAs are continuously released and well mixed with the stool, leading to high repeatability of tests on the same stool sample (31). In addition, the miRNA content is very high in stool samples and is detectable in CRC patients (58). miRNAs are the result of cell exfoliation and easily accumulate in the stool, which makes miRNAs detectable in stool samples (59). miRNAs have also been reported to remain stable in stool samples $(31,60)$. The high content and stability make it possible to detect miRNAs in stool samples $(61,62)$.

In addition to the advantages mentioned above, stool-based miRNA detection also has high sensitivity and specificity (Table I). miR-144* was found to be overexpressed in the feces of CRC patients, indicating that it could be a potential diagnostic marker for CRC detection, with a sensitivity of $74 \%$ and a specificity of $87 \%(n=75, P=0.0001)(60)$. miR-92a and miR-21 were also reported to have these two advantages. miR-92a was found to have a sensitivity of $71.6 \%$ and a specificity of $73.3 \%$, whereas miR-21 had a sensitivity of $55.7 \%$ and a specificity of $73.3 \%$ for CRC (31). Compared with miR-21, miR-92a was able to detect polyps to a great extent and is likely to be a relevant precancerous polyp marker. The level of miR-92a decreased significantly after the removal of the tumor or advanced adenoma, whereas the level of miR-21 decreased only after the removal of the tumor (31). Link et al (59) reported increased expression of miR-21 and miR-106a in CRC stool samples, compared with normal ones. They used a newly developed DMA (direct microRNA analysis) methodology that easily detected miRNAs in the stool. Kalimutho et al (63) found that promoter methylation of $\mathrm{miR}-34 \mathrm{~b} / \mathrm{c}$ and $\mathrm{miR}$ 148a was detected in the feces of CRC patients, suggesting that $\mathrm{miR}-34 \mathrm{~b} / \mathrm{c}$ and $\mathrm{miR}-148 \mathrm{a}$ may be involved in colorectal tumorigenesis and metastasis.

\section{Sputum and pleural effusion miRNA detection in lung cancer}

Non-small cell lung cancer (NSCLC) is the most common type of lung cancer. Lung cancer is the leading cause of cancer- 
Table II. Summary of the characteristics of miRNAs in sputum and pleural effusion.

\begin{tabular}{|c|c|c|c|c|c|c|c|}
\hline Materials & miRNA & Refs. & Dysregulation & Specificity (\%) & Sensitivity (\%) & Samples & Normalization \\
\hline \multirow[t]{9}{*}{ Sputum } & miR-21 & (31) & Upregulated & 100 & 69.7 & 40 & RNU6B \\
\hline & $\operatorname{miR}-155$ & (31) & Upregulated & -- & -- & 40 & RNU6B \\
\hline & miR-486 & (6) & Downregulated & 79.4 & 66.9 & 72 & RNU6B \\
\hline & $\operatorname{miR}-126$ & (6) & Downregulated & 73.8 & 67.2 & 72 & RNU6B \\
\hline & miR-145 & (6) & Downregulated & 82.9 & 59.5 & 72 & RNU6B \\
\hline & miR-21 & (6) & Upregulated & 79.2 & 72.6 & 72 & RNU6B \\
\hline & miR-182 & (6) & Upregulated & 79.5 & 64.3 & 72 & RNU6B \\
\hline & miR-200b & (6) & Upregulated & 78.5 & 62.9 & 72 & RNU6B \\
\hline & miR-375 & (6) & Upregulated & 80.6 & 63.9 & 72 & RNU6B \\
\hline \multirow[t]{8}{*}{ Malignant effusion } & miR-93 & $(75)$ & Downregulated & -- & -- & 184 & ath-miR159a \\
\hline & $\operatorname{miR}-100$ & $(75)$ & Upregulated & -- & -- & 184 & ath-miR159a \\
\hline & $\operatorname{miR}-134$ & $(75)$ & Downregulated & -- & -- & 184 & ath-miR159a \\
\hline & $\operatorname{miR}-151$ & $(75)$ & Downregulated & -- & -- & 184 & ath-miR159a \\
\hline & $\operatorname{miR}-345$ & (75) & Downregulated & -- & -- & 184 & ath-miR159a \\
\hline & miR-24 & $(40)$ & Upregulated & 80.5 & 53.6 & 110 & ath-miR156a \\
\hline & miR-30d & $(40)$ & Upregulated & 67.1 & 71.4 & 110 & ath-miR156a \\
\hline & miR-26a & $(40)$ & Upregulated & -- & -- & 29 & ath-miR156a \\
\hline
\end{tabular}

'--' not mentioned in the original study.

related mortality worldwide $(6,64)$. Therefore, we focused on the application of new miRNA techniques in lung cancer detection. NSCLC can be histologically subdivided into four subtypes: adenocarcinoma, squamous cell carcinoma, large cell carcinoma and 'other' (neuroendocrine cancers, carcinoid tumors) (6). The disease is often diagnosed during the advanced stages and carries a poor prognosis, with a 5-year survival rate of $13 \%(6,32,65)$. However, the survival rate of NSCLC increases to $83 \%$ when detected during stage I. Many methods are currently used to detect and diagnose lung cancer, including computed tomography, magnetic resonance imaging and bronchoscopy (66). Even though the sensitivities of computed tomography (CT) were reported to be as high as $100 \%$ (67-69), the cumulative frequency of subjects with suspicious lesions is high, especially in silicosis patients, in which CT generates a considerable number of false-positive results due to high detection of many non-calcified nodules, which have the potential to be confused with lung cancer (70). These results suggest that although CT is widely used to detect NSCLC, it is plagued by false-positive results at the cost of improved sensitivity (71). Similar to colonoscopy, bronchoscopy is also invasive $(12,72)$. Although sputum cytology is gentle, the low sensitivity limits its wide application. The levels of bronchial epithelial cells, which are detected by sputum cytology, are very low in the sputum (14).

Aside from traditional methods, many studies have reported the use of biological methods, such as molecular genetics, to screen for lung cancer that may meet the standards for an ideal diagnostic method. It has been reported that tissue-based biomarkers can distinguish the tumors which originate in the lung from metastases that originated in other sites in the body by detecting significant biomarkers, such as tumor-suppressor genes, regions of chromosomal amplification, differential
miRNA expression and variable miRNA expression (73-78). However, this method is limited by the accessibility of the specimens and the stability of the assessment offered. Bloodbased biomarkers are another biomarker method that can be used to detect lung cancer. Indeed, blood is an ideal material due to the abundance of cancer-specific biomarkers, such as DNA methylation (79), gene expression (80), blood-miRNA (81), CTC (82) and cell-free DNA. Unfortunately, there are still some drawbacks preventing blood-based biomarkers from being successful clinical biomarkers of cancer, such as low sensitivity, scarce quantities of any given marker, the complex nature of the blood matrix and lack of reproducibility (73). One study attempted to detect specific DNA in the sputum to screen for lung cancer but did not detect any differences in either the free DNA or cellular DNA concentrations in the sputum of lung cancer patients compared with that of healthy controls (83), indicating that DNA in the sputum may not be an effective biomarker for lung cancer.

Many miRNAs have been proven to be abnormally expressed in cancer tissue (57). For this reason, miRNAs are potentially a useful tool for diagnosing and screening human malignancies, including lung cancer (78). Sputum in particular has been considered to be a potential surrogate material for the non-invasive diagnosis of lung cancer. Taken together, these results indicate that miRNAs in the sputum may be used to screen for lung cancer. miRNAs in the sputum can be detected using real-time RT-PCR with TaqMan miRNA assays (Applied Biosystems) (6,32). Sputum miRNAs are very stable $(6,32)$, similar to the stool miRNAs mentioned above. The combination of sputum miRNAs have shown promising results (Table II). miR-21 has been found to be overexpressed in many types of cancer and this finding has been demonstrated in many studies (84). In two recent studies, miR-21 
was reported to have a sensitivity of $72.6 \%$ and a specificity of $79.5 \%$ (32) and a specificity of $69.66 \%$ (95\% CI, 0.46-0.86) and specificity of $100.00 \%$ (95\% CI, 0.77-1.00) (32). Therefore, examination of miR-21 expression had higher sensitivity than that of sputum cytology [47.82\% (95\% CI, 0.27-0.69) sensitivity and $100.00 \%$ (95\% CI, 0.77-1.00) specificity (32)] for the diagnosis and early detection of lung cancer in patients. In addition, it has been reported that increased miR-21 expression is not significantly associated with length of smoking exposure in both cancer patients and controls, suggesting that dysregulation of miR-21 in lung cancer might not be caused by tobacco smoking-related damage (32). Even though overexpression of miR-155 may not distinguish lung cancer patients from controls (32), it is correlated with shortened survival of patients after resection (78). In other words, elevated miR-155 may indicate poor prognosis in lung cancer. Yu et al (6) reported that detection of a combination of different miRNAs (miR-486, miR-21, miR-200b and miR-375) may be a better predictor, with a sensitivity and specificity of 80.6 and $91.7 \%$, when compared with that of a single miRNA (as shown in Table II). Xing et al (65) also showed that detection of a combination of miRNAs (miR-205, miR-210 and miR-708) greatly improve sensitivity and specificity. These two studies indicate that the future detection of miRNAs may involve the detection of a combination rather than a single miRNA. In addition, Yu et al (6) found that miRNA markers had higher diagnostic efficiency for adenocarcinomas than for squamous cell carcinomas of the lung.

Pleural effusion is tightly correlated with NSCLC. Approximately $15 \%$ of cancer patients are diagnosed with malignant pleural effusions (MPEs) during early diagnosis (85). MPEs are an important route of proliferation of tumor cells and are a frequent cause of morbidity in NSCLC in lung cancer (85). MPEs are very crucial for the treatment of NSCLC. Not all patients benefit from chemotherapy, particularly those with short overall survival times (86). There are many methods that can be used to detect MPEs, including cytology, needle biopsy and medical thoracoscopy. Cytology is the standard diagnostic method for malignant effusions. Malignant cells are used as a diagnostic sign, but the quantity of malignant cells may be rather low, limiting the rate of positives ( $\sim 50-70 \%)$, even with repeated testing (87). Although needle biopsy and medical thoracoscopy can improve the sensitivity of diagnosis, their invasiveness and high cost limit their wide use (88). Many studies have reported using biomarkers to detect pleural effusion, such as marker proteins (89), DNA methylation status (90) and cell-free mRNA levels (91), but these methods are limited by their diagnostic accuracy. Research personnel have noticed the close relationship between miRNAs and cancer, thus, they attempted to find evidence that could demonstrate that pleural effusion miRNAs are novel biomarkers for lung cancer diagnosis and early detection (92). However, to the best of our knowledge, few studies have been conducted in this new field of interest. Xie et al (41) demonstrated that the levels of miR-30d, miR-24, miR-26a are higher in malignant effusions compared with normal effusions. miR-152 was first found to be a potential diagnostic biomarker for drug sensitivity since the amounts of miR-152 in tumor cells that were resistant to docetaxel were lower than those of chemosensitive tumor cells (41). Wang et al (86) reported five miRNA expression signatures (high expression levels of miR-100 and low expression levels of miR-134, miR-345, miR-151 and miR-93) that were an independent prognostic marker of poor survival. This was the first report of miRNA expression signatures in MPEs that predicted NSCLC patient prognosis. It seems that using miRNAs as a biomarker to screen for MPE is a promising strategy, yet the mechanism remains unknown. Thus, further study is warranted. In conclusion, detection of miRNAs in the sputum and pleural effusion is a promising method that may be used to prevent lung cancer, both by early detection and accurate prognosis.

\section{Urine miRNA detection in urological cancer}

Bladder cancer is the second most common malignancy of the urinary system. These tumors are often invasive at the time of diagnosis (2). Urothelial carcinoma (UC) is among the five most common malignancies worldwide, and it is also the second leading cause of mortality in patients with genitourinary tract malignancies (93). UCs are the most common histological type of bladder cancer. Ninety-five percent of primary urothelial cell cancers arise from the bladder.

There are several clinical methods that are used to detect bladder cancer. Cystoscopy is currently the standard diagnostic tool, but it is difficult for cystoscopy to detect flat lesions or carcinoma in situ. In addition, the invasive nature and high expense of the procedure restrict it from being widely used $(94,95)$. Urinary cytology may be a useful method for the detection of bladder cancer, due to the non-invasive nature and high specificity of the procedure (90-95\%); however, it has a rather low sensitivity (30-40\%) (96). Therefore, many alternative methods have been presented to diagnose bladder cancer, such as the BTA test, BTA stat test and NMP22 (97-99). These methods have a higher sensitivity (50-70\%) than cystoscopy, but the increased sensitivity comes at the cost of specificity (60-80\%) (95). Even though many achievements have been made in prevention and treatment in recent years, the rates of morbidity and mortality remain high (100). A new biomarker for bladder cancer detection is urgently needed.

As previously discussed, miRNAs are aberrantly expressed or mutated in many types of cancers, suggesting that detection of aberrant miRNA in the urine may be a useful method for bladder cancer screening. In addition, miRNAs have been reported to be stable in the urine and also show high specificity and sensitivity $(95,101-103)$. These characteristics indicate that urinary miRNAs are a potential biomarker for bladder cancer and UC screening. It has been reported that patients with bladder cancer have lower expression of miR-200 family members (miR-200a, miR-200b and miR-200c), miR-192 and miR-155 in the urinary sediment, and higher expression of miR-155 in the urinary supernatant (101). It was also shown that the levels of these miRNAs were altered after surgery. The postsurgical levels of miR-200a, miR-200b, miR-200c, miR-141, miR-429, miR-205, miR-192 and miR-146a increased significantly, whereas the level of miR-155 remained similar (101). Taken together, these results suggest that bladder cancer is the direct cause of depressed urinary miRNA levels, but the mechanism of this suppression is unknown. This study also revealed reverse correlations between the expression of miR-200 family members and EMT markers (ZEB1, vimentin, TGF- $\beta 1$ and 
Table III. Summary of the characteristics of miRNAs in the urine.

\begin{tabular}{llllccc}
\hline miRNA & Refs. & Dysregulation & Specificity (\%) & Sensitivity (\%) & Samples & Normalization \\
\hline miR-143 & $(93)$ & Downregulated & -- & -- & 37 & miR-16 \\
miR-222 & $(93)$ & Upregulated & -- & -- & 37 & miR-16 \\
miR-452 & $(93)$ & Upregulated & -- & -- & 37 & miR-16 \\
miR-96 & $(85)$ & Upregulated & 89.2 & 71 & 149 & RNAU6B \\
miR-183 & $(85)$ & Upregulated & 77.3 & 74 & 149 & RNAU6B \\
miR-200a-b-c & $(91)$ & $\begin{array}{l}\text { Downregulated } \\
\text { (urinary sediment) }\end{array}$ & 52.6 (mir-200a) & 100 (mir-200a) & 75 & $\beta$-glucuronidase and RNU48 \\
miR-192 & $(91)$ & $\begin{array}{l}\text { Downregulated } \\
\text { (urinary sediment) }\end{array}$ & -- & -- & 75 & $\beta$-glucuronidase and RNU48 \\
miR-192 & $(91)$ & $\begin{array}{l}\text { Downregulated } \\
\text { (urinary supernatant) }\end{array}$ & -- & -- & 75 & $\beta$-glucuronidase and RNU48 \\
miR-155 & $(91)$ & $\begin{array}{l}\text { Downregulated } \\
\text { (urinary sediment) }\end{array}$ & -- & -- & 75 & $\beta$-glucuronidase and RNU48 \\
miR-155 & $(91)$ & $\begin{array}{l}\text { Upregulated } \\
\text { (urinary sediment) }\end{array}$ & - & & 75 & $\beta$-glucuronidase and RNU48 \\
\hline
\end{tabular}

'--' not mentioned in the original study.

RhoA) (101). Downregulation of miR-200 family members facilitates EMT of the transitional epithelium and promotes cancer progression (104). This may explain the mechanism, but further study is required. In other studies, miR-452 and miR-222 were reported to play an oncogenic role, while miR-143 was able to function as a tumor suppressor $(103,105-107)$. The present study also revealed that miR-452 may contribute to tumorigenesis and aid in bladder cancer diagnostics, whereas miR-143 and miR-222 may be related to tumor progression and may be used for clinical outcome assessment $(103,107)$. In addition, expression levels of of miR-222 and miR-452 were inversely correlated with ERBB4 expression, while ERBB4 was localized to several cellular counterparts, including the membrane (108), cytoplasm (108) and nucleus (109). miR-222 was correlated with ERBB3 protein expression (103), which is also related to tumor stage, grade, size, growth pattern, recurrence, disease-specificity and overall survival (103). Although the study did not reveal the translocation mechanisms of ERBB3 and ERBB4 in bladder cancer progression, it did reveal the clinical relevance of subcellular protein localization (103), providing new insight into the relationship between miRNA, protein and bladder cancer.

In UC, miR-96 and miR-183 levels in patient urine samples were found to be significantly higher than those of the control group, with $71.0 \%$ sensitivity and $89.2 \%$ specificity, and $74.0 \%$ sensitivity and $77.3 \%$ specificity, respectively. However, more false-positive cases were found in miR-183 detection compared with miR-96 detection, suggesting that miR-183 may be useful as a staging marker but not as a diagnostic marker. miR-183 is upregulated and functions in UTI as well as UC, and miR-96, which has a high sensitivity and specificity, seems to be a tumor biomarker that can be used to distinguish UC patients from non-UC patients (95). The present study also showed that 9 genes involved in activating apoptosis were commonly downregulated in both miR-96 and miR-183 transfectants (95). The characteristics of the miRNAs in the urine are summarized in Table III.

\section{Common methods used in miRNA diagnosis}

The potential of miRNAs in four materials (stool, sputum, pleural effusion and urine) to serve as biomarkers for cancer screening was discussed above. miRNA diagnostic methods are varied (110). In this section of the study, we will focus on the steps that need to be taken to obtain miRNAs and the methods that are used to detect them.

To obtain miRNA profiles, the following steps need to be taken: sample collection, miRNA extraction, miRNA detection, data processing and statistical analysis. Each step is important to the final result. Sample collection is particularly important as it determines the reliability of the results. In this step, researchers should consider many factors, such as age, ethnic group, gender and prior treatments (111). Concerning miRNA extraction, miRNAs can be isolated from samples using three pre-methods: miRNeasy, TRIzol and mirVANA (112). Even though all three methods are suitable for profiling miRNAs from total RNA, researchers still need to be prudent in choosing a method, since small differences exist among the methods and may be a source of bias. miRNA detection is based on the expression levels of miRNAs that have been demonstrated to play a role in disease (111). Researchers should choose the appropriate technology to detect miRNAs using the various available methods. In addition to the detection itself, the stability and reproducibility of the method should also be taken into consideration, to reduce the deviation (113). Data processing mainly refers to the pre-processing of miRNAs for detection and normalization (111), which is necessary to minimize systematic experimental or technical variations. Statistical analysis is the last step and mainly focuses on comparing the differences between groups and indicating the 
Table IV. Features of the common methods used in miRNA diagnosis.

\begin{tabular}{|c|c|c|c|c|}
\hline Method & Refs. & Advantage & Limitation & Improvement \\
\hline $\begin{array}{l}\text { Northern blot } \\
\text { analysis }\end{array}$ & $(105-108)$ & $\begin{array}{l}\text { Gold standard for miRNA } \\
\text { expression profiling } \\
\text { High specificity }\end{array}$ & $\begin{array}{l}\text { Poor sensitivity } \\
\text { Time-consuming } \\
\text { Not practical in a } \\
\text { large amount }\end{array}$ & $\begin{array}{l}\text { The use of locked nucleic acid } \\
\text { (LNA)-modified oligonucleotide } \\
\text { probes (107) }\end{array}$ \\
\hline Bioluminescence & (109) & $\begin{array}{l}\text { Rapid and high-sensitivity } \\
\text { Suitable for application } \\
\text { in clinical diagnostic }\end{array}$ & Complex steps & \\
\hline RT-PCR & $(110,111)$ & $\begin{array}{l}\text { High sensitivity and accuracy } \\
\text { Easy to operate }\end{array}$ & $\begin{array}{l}\text { Expensive } \\
\text { Low throughput }\end{array}$ & $\begin{array}{l}\text { Use of LNA-modified primers (112) } \\
\text { Use of quantitative stem-loop } \\
\text { RT-PCR for the detection } \\
\text { of mature miRNAs (110) }\end{array}$ \\
\hline $\begin{array}{l}\text { Fluorescence } \\
\text { correlation } \\
\text { spectroscopy }\end{array}$ & $(113)$ & $\begin{array}{l}\text { High sensitivity } \\
\text { Low detectable concentration }\end{array}$ & Special equipment is needed & $\begin{array}{l}\text { Use of a dual probe labeling } \\
\text { system (113) }\end{array}$ \\
\hline In situ hybridization & $(114-116)$ & $\begin{array}{l}\text { Specific to the type of cell } \\
\text { Semiquantitative analysis }\end{array}$ & $\begin{array}{l}\text { Low quantification power } \\
\text { Low throughput }\end{array}$ & $\begin{array}{l}\text { LNA miRNA oligo probe (116) } \\
\text { Use of RNA molecules act as a } \\
\text { primer (117) }\end{array}$ \\
\hline Microarray & $(118-120)$ & $\begin{array}{l}\text { High throughput } \\
\text { Widely used }\end{array}$ & $\begin{array}{l}\text { Lack of quantitative data } \\
\text { Expensive equipment }\end{array}$ & $\begin{array}{l}\text { Probe design } \\
\text { Sample labeling } \\
\text { Immobilization chemistry } \\
\text { Microarray chip signal-detection } \\
\text { method }(121,122)\end{array}$ \\
\hline
\end{tabular}

probability that the differences are clinically relevant, using the Student's t-test as many studies have reported $(113,114)$.

Although miRNA detection methods vary, the vast majority of them rely on Watson-Crick base-pairing between complementary chains of nucleotides and hybridization between a strand of nucleic acid and its target miRNA (111). We summarized the advantages, disadvantages and improvements of 6 of the most widely used methods: Northern blot analysis, bioluminescence, RT-PCR, fluorescence correlation spectroscopy, in situ hybridization and microarray (115-132) (Table IV).

\section{Conclusions and prospects}

In the present review, we discussed the possibility of screening miRNAs in the stool, sputum, pleural effusion and urine to distinguish colon cancer, NSCLC and bladder cancer. Other body fluids contain miRNAs as well, such as amniotic fluid, cerebrospinal fluid, colostrums, peritoneal fluid, plasma, saliva, seminal fluid and tears (133). Few studies have reported the relationship between cancer and miRNAs in amniotic fluid, cerebrospinal fluid, colostrums, saliva, peritoneal fluid, seminal fluid and tears. Although many studies have reported the close relationship between plasma miRNAs and cancer, one plasma miRNA has been shown to be altered in multiple types of cancers [e.g. changes in miR-21 in the plasma can potentially indicate colorectal cancer (134) and gastric cancer (135)], which makes the diagnostic value lower than the four materials we listed previously. We did not put much emphasis on the blood biomarker limitations we discussed (low sensitivity, scarce quantity, complex nature and lack of reproducibility). In addition to miRNAs in the blood, a recent study also reported that miR-421 in gastric fluid could be used as a biomarker to screen for gastric cancer, with a sensitivity and specificity that were equal to 71.4 and $71.7 \%$, respectively (136). This study also demonstrated that miRNAs in gastric fluid had superior purity to miRNAs in the plasma. However, it is not easy to obtain gastric fluid in clinical practice and more research on miRNAs in gastric fluid is still needed. Thus, we did not focus on the application of miRNA detection in gastric fluid.

Biomarkers are important for the early detection and prevention of malignancies as they are altered before histological and morphological changes occur. The ideal biomarker must be non-invasive, inexpensive, specific and sensitive to the disease state and a reliable early indication of disease before clinical symptoms appear (133). Even though many biomarkers (most of them are protein) have been used to screen for cancer, they do not function as expected. Improving the diagnostic specificity and sensitivity of proteins is expensive, time-consuming and difficult (133). Meanwhile, miRNA detection is much easier due to PCR or other DNA amplification methods, which can compensate for the low content limits, indicating that miRNAs may be promising biomarkers for screening cancer.

miRNAs are excellent biomarker. The specificity and sensitivity of miRNAs for screening cancer are higher than other biomarkers, particularly the combination of specific miRNAs, as we have previously discussed (Tables I-III). 
Detection of miRNAs is also an inexpensive and rapid method that costs $\sim \$ 10$ (US) and takes $\sim 3.5 \mathrm{~h}$ to obtain the results (95), indicating its possible use to detect tumor biomarkers. In addition, it is a non-invasive method for screening cancer and the materials are easy to obtain.

However, even with all of these advantages, more effort is required to clarify the usefulness of miRNAs. Recent research has focused on the phenomenon of aberrantly expressed miRNAs in related body fluids and feces. The mechanisms of action remain unknown, suggesting that the mechanisms require future investigation. In addition, it is not easy to identify miRNA target genes. A single miRNA may regulate the transcription of more than one mRNA, and one specific mRNA may be regulated by several miRNAs $(103,137)$, making it difficult to determine a particular miRNA. In many studies, RNU6B was reported to be an endogenous control that could be used to normalize the expression of miRNAs in tissue specimens, but to the best of our knowledge, it may not be the ideal endogenous control for miRNAs due to its rapid degradation in samples (such as stool) (138) and uncertain changes in the content (95). Therefore, it is important to find a stable powerful endogenous control. Although several studies have proposed solutions $(59,95)$, further examination is required.

In conclusion, miRNA detection is a promising method for cancer screening. Many opportunities and challenges lie ahead. We believe that miRNA-based detection will be used for cancer screening in the near future.

\section{Acknowledgements}

The present study was supported by grants from the National Natural Science Foundation of China (no. 81272689), and the Chongqing Science Fund for Distinguished Young Scholars (CSTC, 2009BA5045).

\section{References}

1. Corte H, Manceau G, Blons H and Laurent-Puig P: MicroRNA and colorectal cancer. Digest Liver Dis 44: 195-200, 2012.

2. Jemal A, Siegel R, Ward E, Hao YP, Xu JQ and Thun MJ: Cancer Statistics, 2009. CA Cancer J Clin 59: 225-249, 2009.

3. Frost JK, Ball WC Jr, Levin ML, et al: Early lung cancer detection: results of the initial (prevalence) radiologic and cytologic screening in the Johns Hopkins study. Am Rev Respir Dis 130: 549-554, 1984.

4. Flehinger BJ, Kimmel M and Melamed MR: The effect of surgical treatment on survival from early lung cancer. Implications for screening. Chest 101: 1013-1018, 1992.

5. Patz EF Jr, Rossi S, Harpole DH Jr, Herndon JE and Goodman PC: Correlation of tumor size and survival in patients with stage IA non-small cell lung cancer. Chest 117: 1568-1571, 2000.

6. Yu L, Todd NW, Xing LX, et al: Early detection of lung adenocarcinoma in sputum by a panel of microRNA markers. Int J Cancer 127: 2870-2878, 2010.

7. Subramanian J and Simon R: Gene expression-based prognostic signatures in lung cancer: ready for clinical use? J Natl Cancer Inst 102: 464-474, 2010.

8. Greer KB and Cooper GS: Receipt of colonoscopy is key to reduction of colorectal cancer mortality. Gastrointest Endosc 76: 365-366, 2012.

9. Chang KC and Yew WW: What is the role of autofluorescence bronchoscopy in screening lung cancer among silicotic subjects? reply. Int J Tuberc Lung Dis 15: 1277-1278, 2011.

10. Blick CG, Nazir SA, Mallett S, et al: Evaluation of diagnostic strategies for bladder cancer using computed tomography (CT) urography, flexible cystoscopy and voided urine cytology: results for 778 patients from a hospital haematuria clinic. BJU Int 110: 84-94, 2012.
11. Ladabaum U and Song K: Projected national impact of colorectal cancer screening on clinical and economic outcomes and health services demand. Gastroenterology 129: 1151-1162, 2005.

12. Toloza EM, Harpole L and McCrory DC: Noninvasive staging of non-small cell lung cancer: a review of the current evidence. Chest 123: 137S-146S, 2003.

13. van Rhijn BW, van der Poel HG and van der Kwast TH: Urine markers for bladder cancer surveillance: a systematic review. Eur Urol 47: 736-748, 2005.

14. Thunnissen FB: Sputum examination for early detection of lung cancer. J Clin Pathol 56: 805-810, 2003.

15. Simon MA, Lokeshwar VB and Soloway MS: Current bladder cancer tests: unnecessary or beneficial? Crit Rev Oncol Hematol 47: 91-107, 2003.

16. Bassi P, De Marco V, De Lisa A, et al: Non-invasive diagnostic tests for bladder cancer: a review of the literature. Urol Int 75: 193-200, 2005.

17. Esquela-Kerscher A and Slack FJ: Oncomirs - microRNAs with a role in cancer. Nat Rev Cancer 6: 259-269, 2006.

18. Shenouda SK and Alahari SK: MicroRNA function in cancer: oncogene or a tumor suppressor? Cancer Metastasis Rev 28: 369-378, 2009.

19. Patnaik SK, Kannisto E, Mallick R and Yendamuri S: Overexpression of the lung cancer-prognostic $m i R-146 b$ microRNAs has a minimal and negative effect on the malignant phenotype of A549 lung cancer cells. PLoS One 6: e22379, 2011.

20. Kong YW, Ferland-McCollough D, Jackson TJ and Bushell M: microRNAs in cancer management. Lancet Oncol 13: E249-E258, 2012.

21. Calin GA and Croce CM: MicroRNA signatures in human cancers. Nat Rev Cancer 6: 857-866, 2006.

22. Bartel DP: MicroRNAs: genomics, biogenesis, mechanism, and function. Cell 116: 281-297, 2004.

23. Harfe BD: MicroRNAs in vertebrate development. Curr Opin Genet Dev 15: 410-415, 2005.

24. Kloosterman WP and Plasterk RHA: The diverse functions of microRNAs in animal development and disease. Dev Cell 11: 441-450, 2006.

25. Mandke P, Wyatt N, Fraser J, Bates B, Berberich SJ and Markey MP: MicroRNA-34a modulates MDM4 expression via a target site in the open reading frame. PLoS One 7: e42034, 2012.

26. Lewis BP, Burge CB and Bartel DP: Conserved seed pairing, often flanked by adenosines, indicates that thousands of human genes are microRNA targets. Cell 120: 15-20, 2005.

27. Chen X, Ba Y, Ma L, et al: Characterization of microRNAs in serum: a novel class of biomarkers for diagnosis of cancer and other diseases. Cell Res 18: 997-1006, 2008.

28. Mitchell PS, Parkin RK, Kroh EM, et al: Circulating microRNAs as stable blood-based markers for cancer detection. Proc Natl Acad Sci USA 105: 10513-10518, 2008.

29. Taylor DD and Gercel-Taylor C: MicroRNA signatures of tumorderived exosomes as diagnostic biomarkers of ovarian cancer. Gynecol Oncol 110: 13-21, 2008.

30. Ho AS, Huang X, Cao HB, et al: Circulating miR-210 as a novel hypoxia marker in pancreatic cancer. Transl Oncol 3: 109-113, 2010.

31. Wu CW, Ng SSM, Dong YJ, et al: Detection of miR-92a and miR-21 in stool samples as potential screening biomarkers for colorectal cancer and polyps. Gut 61: 739-745, 2012.

32. Xie Y, Todd NW, Liu ZQ, et al: Altered miRNA expression in sputum for diagnosis of non-small cell lung cancer. Lung Cancer 67: 170-176, 2010.

33. Brase JC, Wuttig D, Kuner R and Sultmann H: Serum microRNAs as non-invasive biomarkers for cancer. Mol Cancer 9: 306, 2010.

34. Caby MP, Lankar D, Vincendeau-Scherrer C, Raposo G and Bonnerot C: Exosomal-like vesicles are present in human blood plasma. Int Immunol 17: 879-887, 2005.

35. van Niel G, Porto-Carreiro I, Simoes S and Raposo G: Exosomes: a common pathway for a specialized function. J Biochem 140: 13-21, 2006.

36. Valadi H, Ekstrom K, Bossios A, Sjostrand M, Lee JJ and Lotvall JO: Exosome-mediated transfer of mRNAs and microRNAs is a novel mechanism of genetic exchange between cells. Nat Cell Biol 9: 654-672, 2007.

37. Hunter MP, Ismail N, Zhang X, et al: Detection of microRNA expression in human peripheral blood microvesicles. PLoS One 3: e3694, 2008.

38. Rabinowits G, Gercel-Taylor C, Day JM, Taylor DD and Kloecker GH: Exosomal microRNA: a diagnostic marker for lung cancer. Clin Lung Cancer 10: 42-46, 2009. 
39. Skog J, Wurdinger T, van Rijn S, et al: Glioblastoma microvesicles transport RNA and proteins that promote tumour growth and provide diagnostic biomarkers. Nat Cell Biol 10: 1470-1476, 2008.

40. Yu Z and Hecht NB: The DNA/RNA-binding protein, translin, binds microRNA122a and increases its in vivo stability. J Androl 29: 572-579, 2008.

41. Xie L, Chen X, Wang L, et al: Cell-free miRNAs may indicate diagnosis and docetaxel sensitivity of tumor cells in malignant effusions. BMC Cancer 10: 591, 2010

42. Levine JS and Ahnen DJ: Clinical practice. Adenomatous polyps of the colon. N Engl J Med 355: 2551-2557, 2006.

43. Levin B, Lieberman DA, McFarland B, et al: Screening and surveillance for the early detection of colorectal cancer and adenomatous polyps, 2008: a joint guideline from the American Cancer Society, the US Multi-Society Task Force on Colorectal Cancer, and the American College of Radiology. Gastroenterology 134: 1570-1595, 2008.

44. Lieberman DA and Weiss DG: One-time screening for colorectal cancer with combined fecal occult-blood testing and examination of the distal colon. N Engl J Med 345: 555-560, 2001.

45. Imperiale TF, Ransohoff DF, Itzkowitz SH, Turnbull BA and Ross ME: Fecal DNA versus fecal occult blood for colorectalcancer screening in an average-risk population. N Engl J Med 351: 2704-2714, 2004

46. Hewitson P, Glasziou P, Irwig L, Towler B and Watson E: Screening for colorectal cancer using the faecal occult blood test Hemoccult. Cochrane Database Syst Rev: CD001216, 2007. doi: 10.1002/14651858.CD001216.pub2.

47. Cotton PB, Durkalski VL, Benoit PC, et al: Computed tomographic colonography (virtual colonoscopy): a multicenter comparison with standard colonoscopy for detection of colorecta neoplasia. JAMA 291: 1713-1719, 2004.

48. Mulhall BP, Veerappan GR and Jackson JL: Meta-analysis: computed tomographic colonography. Ann Intern Med 142: 635-650, 2005

49. Johnson CD, Chen MH, Toledano AY, et al: Accuracy of CT colonography for detection of large adenomas and cancers. New Engl J Med 359: 1207-1217, 2008.

50. Coady-Fariborzian L, Angel LP and Procaccino JA: Perforated colon secondary to virtual colonoscopy: report of a case. Dis Colon Rectum 47: 1247-1249, 2004

51. Kanaoka S, Yoshida K, Miura N, Sugimura H and Kajimura M Potential usefulness of detecting cyclooxygenase 2 messenger RNA in feces for colorectal cancer screening. Gastroenterology 127: 422-427, 2004

52. Ahlquist DA, Sargent DJ, Loprinzi CL, et al: Stool DNA and occult blood testing for screen detection of colorectal neoplasia. Ann Intern Med 149: 441-450, W481, 2008.

53. Brand RE, Ross ME and Shuber AP: Reproducibility of a multitarget stool-based DNA assay for colorectal cancer detection. Am J Gastroenterol 99: 1338-1341, 2004.

54. Calistri D, Rengucci C, Bocchini R, Saragoni L, Zoli W and Amadori D: Fecal multiple molecular tests to detect colorectal cancer in stool. Clin Gastroenterol Hepatol 1: 377-383, 2003.

55. Yu YJ, Majumdar AP, Nechvatal JM, et al: Exfoliated cells in stool: a source for reverse transcription-PCR-based analysis of biomarkers of gastrointestinal cancer. Cancer Epidemiol Biomarkers Prev 17: 455-458, 2008

56. Zauber AG, Levin TR, Jaffe CC, Galen BA, Ransohoff DF and Brown ML: Implications of new colorectal cancer screening technologies for primary care practice. Med Care 46: S138-S146, 2008.

57. Aslam MI, Taylor K, Pringle JH and Jameson JS: MicroRNAs are novel biomarkers of colorectal cancer. Br J Surg 96: 702-710, 2009.

58. Ahmed FE, Jeffries CD, Vos PW, et al: Diagnostic microRNA markers for screening sporadic human colon cancer and active ulcerative colitis in stool and tissue. Cancer Genomics Proteomics 6: 281-295, 2009

59. Link A, Balaguer F, Shen Y, et al: Fecal MicroRNAs as novel biomarkers for colon cancer screening. Cancer Epidemiol Biomarkers Prev 19: 1766-1774, 2010.

60. Kalimutho M, Del Vecchio Blanco G, Di Cecilia S, et al: Differential expression of miR-144* as a novel fecal-based diagnostic marker for colorectal cancer. J Gastroenterol 46 1391-1402, 2011.

61. Koga Y, Yasunaga M, Takahashi A, et al: MicroRNA expression profiling of exfoliated colonocytes isolated from feces for colorectal cancer screening. Cancer Prev Res 3: 1435-1442, 2010.
62. Li JM, Zhao RH, Li ST, et al: Down-regulation of fecal miR-143 and miR-145 as potential markers for colorectal cancer. Saudi Med J 33: 24-29, 2012.

63. Kalimutho M, Di Cecilia S, Blanco GD, et al: Epigenetically silenced $\mathrm{miR}-34 \mathrm{~b} / \mathrm{c}$ as a novel faecal-based screening marker for colorectal cancer. Br J Cancer 104: 1770-1778, 2011.

64. Greenlee RT, Hill-Harmon MB, Murray T and Thun M: Cancer statistics, 2001. CA Cancer J Clin 51: 15-36, 2001.

65. Xing LX, Todd NW, Yu L, Fang HB and Jiang F: Early detection of squamous cell lung cancer in sputum by a panel of microRNA markers. Modern Pathol 23: 1157-1164, 2010.

66. Akira M: High-resolution CT in the evaluation of occupational and environmental disease. Radiol Clin North Am 40: 43-59, 2002.

67. Bastarrika G, Garcia-Velloso MJ, Lozano MD, et al: Early lung cancer detection using spiral computed tomography and positron emission tomography. Am J Respir Crit Care Med 171: $1378-1383,2005$

68. Gohagan JK, Marcus PM, Fagerstrom RM, et al: Final results of the Lung Screening Study, a randomized feasibility study of spiral CT versus chest X-ray screening for lung cancer. Lung Cancer 47: 9-15, 2005

69. Swensen SJ, Jett JR, Hartman TE, et al: Lung cancer screening with CT: Mayo Clinic experience. Radiology 226: 756-761, 2003.

70. Koga H, Eguchi K, Shinkai T, et al: Preliminary evaluation of the new tumor marker, CYFRA 21-1, in lung cancer patients. Jpn J Clin Oncol 24: 263-268, 1994.

71. Sun S, Schiller JH and Gazdar AF: Lung cancer in never smokers: a different disease. Nat Rev Cancer 7: 778-790, 2007.

72. Hirsch FR, Franklin WA, Gazdar AF and Bunn PA Jr: Early detection of lung cancer: clinical perspectives of recent advances in biology and radiology. Clin Cancer Res 7: 5-22, 2001.

73. Hassanein M, Callison JC, Callaway-Lane C, Aldrich MC, Grogan EL and Massion PP: The state of molecular biomarkers for the early detection of lung cancer. Cancer Prev Res 5: 992-1006, 2012.

74. Belinsky SA: Gene-promoter hypermethylation as a biomarker in lung cancer. Nat Rev Cancer 4: 707-717, 2004.

75. Castro M, Grau L, Puerta P, et al: Multiplexed methylation profiles of tumor suppressor genes and clinical outcome in lung cancer. J Transl Med 8: 86, 2010

76. Halling KC, Rickman OB, Kipp BR, Harwood AR, Doerr CH and Jett JR: A comparison of cytology and fluorescence in situ hybridization for the detection of lung cancer in bronchoscopic specimens. Chest 130: 694-701, 2006.

77. Beane J, Sebastiani P, Whitfield TH, et al: A prediction model for lung cancer diagnosis that integrates genomic and clinical features. Cancer Prev Res 1: 56-64, 2008.

78. Yanaihara N, Caplen N, Bowman E, et al: Unique microRNA molecular profiles in lung cancer diagnosis and prognosis. Cancer Cell 9: 189-198, 2006.

79. Greenberg AK, Rimal B, Felner K, et al: S-adenosylmethionine as a biomarker for the early detection of lung cancer. Chest 132 : $1247-1252,2007$

80. Showe MK, Vachani A, Kossenkov AV, et al: Gene expression profiles in peripheral blood mononuclear cells can distinguish patients with non-small cell lung cancer from patients with nonmalignant lung disease. Cancer Res 69: 9202-9210, 2009.

81. Lai CY, Yu SL, Hsieh MH, et al: MicroRNA expression aberration as potential peripheral blood biomarkers for schizophrenia. PLoS One 6: e21635, 2011.

82. Peck K, Sher YP, Shih JY, Roffler SR, Wu CW and Yang PC Detection and quantitation of circulating cancer cells in the peripheral blood of lung cancer patients. Cancer Res 58: 2761-2765, 1998

83. van der Drift MA, Prinsen CFM, Hol BEA, et al: Can free DNA be detected in sputum of lung cancer patients? Lung Cancer 61: 385-390, 2008

84. Zhu S, Si ML, Wu H and Mo YY: MicroRNA-21 targets the tumor suppressor gene tropomyosin 1 (TPM1). J Biol Chem 282: 14328-14336, 2007.

85. Neragi-Miandoab S: Malignant pleural effusion, current and evolving approaches for its diagnosis and management. Lung Cancer 54: 1-9, 2006.

86. Wang T, Lv M, Shen S, et al: Cell-free microRNA expression profiles in malignant effusion associated with patient survival in non-small cell lung cancer. PLoS One 7: e43268, 2012.

87. Lee JH, Hong YS, Ryu JS and Chang JH: p53 and FHIT mutations and microsatellite alterations in malignancy-associated pleural effusion. Lung Cancer 44: 33-42, 2004 
88. Spector M and Pollak JS: Management of malignant pleural effusions. Semin Respir Crit Care Med 29: 405-413, 2008.

89. Topolcan O, Holubec L, Polivkova V, et al: Tumor markers in pleural effusions. Anticancer Res 27: 1921-1924, 2007.

90. Katayama H, Hiraki A, Aoe K, et al: Aberrant promoter methylation in pleural fluid DNA for diagnosis of malignant pleural effusion. Int J Cancer 120: 2191-2195, 2007.

91. Wang T, Qian X, Wang Z, et al: Detection of cell-free BIRC5 mRNA in effusions and its potential diagnostic value for differentiating malignant and benign effusions. Int J Cancer 125 1921-1925, 2009.

92. Nair VS, Maeda LS and Ioannidis JPA: Clinical outcome prediction by microRNAs in human cancer: a systematic review. J Natl Cancer Inst 104: 528-540, 2012.

93. Jemal A, Siegel R, Xu J and Ward E: Cancer statistics, 2010. CA Cancer J Clin 60: 277-300, 2010.

94. Snowdon J, Boag S, Feilotter H, Izard J and Siemens DR: A pilot study of urinary microRNA as a biomarker for urothelial cancer. Can Urol Assoc J 7: 28-32, 2013.

95. Yamada Y, Enokida H, Kojima S, et al: MiR-96 and miR-183 detection in urine serve as potential tumor markers of urothelia carcinoma: correlation with stage and grade, and comparison with urinary cytology. Cancer Sci 102: 522-529, 2011.

96. Ratliff TL: Urine markers for bladder cancer surveillance: a systematic review. J Urol 174: 2065-2066, 2005.

97. Sarosdy MF, Hudson MA, Ellis WJ, et al: Improved detection of recurrent bladder cancer using the Bard BTA stat Test. Urology 50: 349-353, 1997.

98. Carpinito GA, Stadler WM, Briggman JV, et al: Urinary nuclear matrix protein as a marker for transitional cell carcinoma of the urinary tract. J Urol 156: 1280-1285, 1996.

99. Fradet Y and Lockhard C: Performance characteristics of a new monoclonal antibody test for bladder cancer: ImmunoCyt ${ }^{\mathrm{TM}}$. Can J Urol 4: 400-405, 1997.

100. Greenlee RT, Murray T, Bolden S and Wingo PA: Cancer statistics, 2000. CA Cancer J Clin 50: 7-33, 2000.

101. Wang G, Chan ESY, Kwan BCH, et al: Expression of microRNAs in the urine of patients with bladder cancer. Clin Genitourin Cancer 10: 106-113, 2012.

102. Roos PH and Jakubowski N: Methods for the discovery of lowabundance biomarkers for urinary bladder cancer in biological fluids. Bioanalysis 2: 295-309, 2010.

103. Puerta-Gil P, Garcia-Baquero R, Jia AY, et al: miR-143, miR-222, and miR-452 are useful as tumor stratification and noninvasive diagnostic biomarkers for bladder cancer. Am J Pathol 180 1808-1815, 2012.

104. Hanke M, Hoefig K, Merz H, et al: A robust methodology to study urine microRNA as tumor marker: microRNA-126 and microRNA-182 are related to urinary bladder cancer. Urol Oncol 28: 655-661, 2010.

105. Veerla S, Lindgren D, Kvist A, et al: MiRNA expression in urothelial carcinomas: important roles of miR-10a, miR-222, miR-125b, miR-7 and miR-452 for tumor stage and metastasis, and frequent homozygous losses of miR-31. Int J Cancer 124 2236-2242, 2009

106. Han Y, Chen J, Zhao X, et al: MicroRNA expression signatures of bladder cancer revealed by deep sequencing. PLoS One 6 e18286, 2011.

107. Noguchi S, Mori T, Hoshino Y, et al: MicroRNA-143 functions as a tumor suppressor in human bladder cancer T24 cells. Cancer Lett 307: 211-220, 2011.

108. Kassouf W, Black PC, Tuziak T, et al: Distinctive expression pattern of ErbB family receptors signifies an aggressive variant of bladder cancer. J Urol 179: 353-358, 2008.

109. Junttila TT, Laato M, Vahlberg T, et al: Identification of patients with transitional cell carcinoma of the bladder overexpressing ErbB2, ErbB3, or specific ErbB4 isoforms: real-time reverse transcription-PCR analysis in estimation of ErbB receptor status from cancer patients. Clin Cancer Res 9: 5346-5357, 2003

110. Cissell KA and Deo SK: Trends in microRNA detection. Anal Bioanal Chem 394: 1109-1116, 2009.

111. de Planell-Saguer M and Rodicio MC: Analytical aspects of microRNA in diagnostics: a review. Anal Chim Acta 699: 134-152, 2011

112. Ach RA, Wang H and Curry B: Measuring microRNAs: comparisons of microarray and quantitative PCR measurements, and of different total RNA prep methods. BMC Biotechnol 8: 69, 2008

113. de Planell-Saguer M and Rodicio MC: Analytical aspects of microRNA in diagnostics: a review. Anal Chim Acta 699: 134-152, 2011.
114. Sarver AL: Toward understanding the informatics and statistical aspects of micro-RNA profiling. J Cardiovasc Transl Res 3: 204-211, 2010.

115. Valoczi A, Hornyik C, Varga N, Burgyan J, Kauppinen S and Havelda Z: Sensitive and specific detection of microRNAs by northern blot analysis using LNA-modified oligonucleotide probes. Nucleic Acids Res 32: e175, 2004.

116. Pall GS, Codony-Servat C, Byrne J, Ritchie L and Hamilton A: Carbodiimide-mediated cross-linking of RNA to nylon membranes improves the detection of siRNA, miRNA and piRNA by northern blot. Nucleic Acids Res 35: e60, 2007.

117. Varallyay E, Burgyan J and Havelda Z: MicroRNA detection by northern blotting using locked nucleic acid probes. Nat Protoc 3 190-196, 2008

118. Chamnongpol S, Maroney PA and Nilsen TW: A rapid, quantitative assay for direct detection of microRNAs and other small RNAs using splinted ligation. Methods Mol Biol 667: 3-17, 2010

119. Cissell KA, Rahimi Y, Shrestha S, Hunt EA and Deo SK: Bioluminescence-based detection of microRNA, miR21 in breast cancer cells. Anal Chem 80: 2319-2325, 2008.

120. Chen C, Ridzon DA, Broomer AJ, et al: Real-time quantification of microRNAs by stem-loop RT-PCR. Nucleic Acids Res 33 e179, 2005

121. Weaver S, Dube S, Mir A, et al: Taking qPCR to a higher level: analysis of CNV reveals the power of high throughput qPCR to enhance quantitative resolution. Methods 50: 271-276, 2010.

122. Raymond CK, Roberts BS, Garrett-Engele P, Lim LP and Johnson JM: Simple, quantitative primer-extension PCR assay for direct monitoring of microRNAs and short-interfering RNAs. RNA 11: 1737-1744, 2005.

123. Neely LA, Patel S, Garver J, et al: A single-molecule method for the quantitation of microRNA gene expression. Nat Methods 3 41-46, 2006

124. Kloosterman WP, Wienholds E, de Bruijn E, Kauppinen S and Plasterk RHA: In situ detection of miRNAs in animal embryos using LNA-modified oligonucteotide probes. Nat Methods 3 : 27-29, 2006.

125. de Planell-Saguer M, Rodicio MC and Mourelatos Z: Rapid in situ codetection of noncoding RNAs and proteins in cells and formalin-fixed paraffin-embedded tissue sections without protease treatment. Nat Protoc 5: 1061-1073, 2010.

126. Obernosterer G, Martinez J and Alenius M: Locked nucleic acid-based in situ detection of microRNAs in mouse tissue sections. Nat Protoc 2: 1508-1514, 2007.

127. Nelson PT, Baldwin DA, Kloosterman WP, Kauppinen S, Plasterk RHA and Mourelatos Z: RAKE and LNA-ISH reveal microRNA expression and localization in archival human brain. RNA 12: 187-191, 2006.

128. Liu CG, Calin GA, Volinia S and Croce CM: MicroRNA expression profiling using microarrays. Nat Protoc 3: 563-578, 2008.

129. Li W and Ruan KC: MicroRNA detection by microarray. Anal Bioanal Chem 394: 1117-1124, 2009.

130. Nelson PT, Baldwin DA, Scearce LM, Oberholtzer JC, Tobias JW and Mourelatos Z: Microarray-based, high-throughput gene expression profiling of microRNAs. Nat Methods 1: 155-161, 2004

131. Takada S and Mano H: Profiling of microRNA expression by mRAP. Nat Protoc 2: 3136-3145, 2007.

132. Volinia S, Calin GA, Liu CG, et al: A microRNA expression signature of human solid tumors defines cancer gene targets. Proc Natl Acad Sci USA 103: 2257-2261, 2006.

133. Weber JA, Baxter DH, Zhang SL, et al: The microRNA spectrum in 12 body fluids. Clin Chem 56: 1733-1741, 2010.

134. Kanaan Z, Rai SN, Eichenberger MR, et al: Plasma miR-21: a potential diagnostic marker of colorectal cancer. Ann Surg 256 544-551, 2012

135. Li BS, Zhao YL, Guo G, et al: Plasma microRNAs, miR-223, miR-21 and miR-218, as novel potential biomarkers for gastric cancer detection. PLoS One 7: e41629, 2012.

136. Zhang X, Cui L, Ye G, et al: Gastric juice microRNA-421 is a new biomarker for screening gastric cancer. Tumour Biol 33 2349-2355, 2012.

137. Janakiram NB and Rao CV: Molecular markers and targets for colorectal cancer prevention. Acta Pharmacol Sin 29: 1-20, 2008 .

138. Dong Y, Wu WK, Wu CW, Sung JJ, Yu J and Ng SS: MicroRNA dysregulation in colorectal cancer: a clinical perspective. Br J Cancer 104: 893-898, 2011. 